\title{
SIFAT FISIKA DAN MORFOLOGI NANOKOMPOSIT \\ ABS/PC DENGAN FILLER NANO PRECIPITATED \\ CALCIUM CARBONATE (NPCC)
}

\section{THE PHYSICAL AND MORPHOLOGICAL PROPERTIES OF ABS/PC NANOCOMPOSITES CONTAINING NANOFILLER NPCC}

\author{
Dwi Wahini Nurhajati*, Ike Setyorini, Sugihartono \\ Balai Besar Kulit, Karet, dan Plastik, Yogyakarta \\ *E-mail: dwiwahini@yahoo.com
}

Diterima: 20 Februari 2014 Direvisi: 4 April 2014 Disetujui: 11 April 2014

\begin{abstract}
The purpose of this research was to study the effect of blend ratios of acrylonitrile butadiene styrene $(A B S)$ and polycarbonate $(P C)$ in the different amount of nanoprecipitated calcium carbonate (NPCC) on the physical properties of ABS/PC nanocomposites. Nanocomposites were prepared in varied ratio of $A B S / P C 100 / 0 ; 90 / 10 ; 80 / 20 ; 70 / 30$ and varied amount of NPCC 0; 2.5; and 5 phr (per hundred resin), Nanocomposites were made by melt compounding in the Laboplastomill internal mixer at $200^{\circ} \mathrm{C}$ for 10 minutes. The SEM micrographs showed homogeneous dispersion of the nanocomposite materials and did not show aglomeration of NPCC. The best nanocomposite was a nanocomposite containing the ABS/PC 90/10 with NPCC 2.5 phr perfomed with impact resistance $5030 \mathrm{~J} / \mathrm{m}^{2}$, tensile strength $380.14 \mathrm{~kg} / \mathrm{cm}^{2}$, elongation at break $3.59 \%$, density $1.16 \mathrm{~g} / \mathrm{cm}^{3}$, and hardness 85 Shore D.
\end{abstract}

Keywords: nanocomposites, ABS/PC, NPCC, physical properties, morphology

\begin{abstract}
ABSTRAK
Penelitian ini bertujuan untuk mempelajari pengaruh perbandingan plastik acrylonitrile butadiene styrene (ABS) dan polikarbonat (PC) serta jumlah bahan pengisi nanoprecipitated calcium carbonate (NPCC) terhadap sifat fisika nanokomposit ABS/PC. Nanokomposit dibuat dengan variasi rasio ABS/PC yaitu 100/0; 90/10; 80/20; dan 70/30 serta variasi jumlah (NPCC) yaitu $0 ; 2,5 ;$ dan 5 phr (per hundred resin). Nanokomposit dibuat dengan menggunakan Laboplastomill internal mixer pada suhu $200^{\circ} \mathrm{C}$ dan waktu 10 menit. Hasil mikrograf SEM menunjukkan bahwa bahan penyusun nanokomposit tercampur homogen dan tidak terlihat NPCC teraglomerasi. Hasil penelitian terbaik adalah nanokomposit yang berisi $\mathrm{ABS} / \mathrm{PC}=90 / 10$ dan 2,5 phr NPCC dengan hasil uji ketahanan pukul $5030 \mathrm{~J} / \mathrm{m}^{2}$, kuat tarik $380,14 \mathrm{~kg} / \mathrm{cm}^{2}$, perpanjangan putus $3,59 \%$, densitas $1,16 \mathrm{~g} / \mathrm{cm}^{3}$, dan kekerasan 85 Shore D.
\end{abstract}

Kata kunci: nanokomposit, ABS/PC, NPCC, sifat fisika, morfologi

\section{PENDAHULUAN}

Acrylonitrile butadiene styrene (ABS) dan polikarbonat (PC) merupakan bahan termoplastik yang banyak digunakan di industri otomotif, komputer dan peralatan industri lainnya. ABS mempunyai keunggulan sifat mekanis dan ketahanan terhadap bahan kimia yang baik, liat, keras, tahan korosi, mudah diproses dengan berbagai bentuk, dapat dielektroplating dan direkatkan, serta biaya proses murah meskipun memiliki sifat tahan pukul lebih rendah dari polikarbonat. PC merupakan bahan termoplastik yang mempunyai ketahanan pukul tertinggi, selain itu juga memiliki keunggulan 
mudah dibentuk dengan menggunakan panas (easily thermoformed), ketahanan termal yang baik, tahan terhadap benturan, ringan, memiliki keseimbangan yang baik antara kekerasan, stabilitas dimensi dan transparansi secara optikal. Akan tetapi PC memiliki kelemahan yaitu cukup mudah tergores, ketahanan terhadap pelarut rendah, processability dan sensitifitas takikan kurang, serta harganya mahal. Jika ABS akan digunakan untuk membuat barang-barang plastik sebagai pengganti logam di industri otomotif maupun sepatu pengaman, diperlukan modifikasi untuk menaikkan sifat ketahanan pukulnya. Oleh karena itu, ABS perlu dicampur dengan bahan plastik yang mempunyai ketahanan pukul tinggi seperti PC. Kombinasi sifat terbaik dari ABS dan PC diharapkan menghasilkan campuran polipaduan $\mathrm{ABS} / \mathrm{PC}$ yang dapat dikembangkan secara komersial.

Penelitian tentang campuran ABS/PC telah dilaporkan oleh Hassan and Jwu (2005) dimana pencampuran optimum pada perbandingan ABS/ PC 40/60. Menurut penelitian Farzadfar and Khorasani (2011), penggunaan ABS-g-MAH sebagai compatibilizer sebanyak $20 \mathrm{phr}$ pada proses pencampuran PC/ABS dapat menaikkan sifat kekuatan tarik dan ketahanan pukul. Penelitian tentang polipaduan PC/ABS dengan penggandeng maleic anhydride-grafted polypropylene (MAPP) dan resin epoksi telah dilakukan oleh Krache and Debbah (2011), dan Mahanta et al. (2012) yang menggunakan plastik PC dan ABS daur ulang dengan bahan penggandeng MAPP dimana hasilnya menunjukkan tensile modulus PC naik dengan bertambahnya ABS, namun ada penurunan ketahanan impak. Oleh karena itu, perlu ditambahkan filler yang dapat menaikkan beberapa sifat plastik misalnya nanofiller. Menurut Gupta and Bhattacharya (2008) penambahan filler dan reinforcements memegang peranan penting dalam industri polimer. Banyak jenis filler yang dapat ditambahkan kedalam polimer untuk dapat memperbaiki sifat mudah diproses dan sifat produk akhir seperti kekuatan tarik, heat distortion temperatures, thermal conductivity, electrical conductivity, dan gas barrier. Penambahan filler ukuran nano diharapkan lebih memperbaiki sifat mekanik, termal, dan barrier. Saat ini pengisi berukuran nano telah menjadi pendekatan yang menarik untuk meningkatkan sifat polimer. Bahan komposit yang berisi pengisi berukuran nano disebut nanokomposit (Abubakar and Rosli, 2006). Salah satu filler berukuran nano yang banyak digunakan di industri plastik adalah precipitated calcium carbonate (PCC). Penggunaan $\mathrm{CaCO}_{3}$ yang permukaannya telah dilapisi dengan coupling agent dapat memperbaiki kuat tarik dan kuat impak plastik HDPE telah dilaporkan oleh Phueakbuakhao et al. (2008). Pengaruh metode proses terhadap morfologi dan reologi dari nanokomposit $\mathrm{PC} / \mathrm{CaCO}_{3}$ telah diteliti oleh Chao et al. (2009). Wang et al. (2008) telah mempelajari sifat-sifat nanokomposit dari $\mathrm{CaCO}_{3} / \mathrm{ABS}$ dan $\mathrm{CaCO}_{3} /$ ethylene-vinyl acetate copolymer (EVA)/ABS. Hasil penelitian menunjukkan bahwa nanopartikel $\mathrm{CaCO}_{3}$ dapat menaikkan flexural modulus dari nanokomposit $\mathrm{CaCO}_{3} / \mathrm{EVA} / \mathrm{ABS}$ dan menjaga atau menaikkan ketahanan pukul impak pada kisaran jumlah tertentu dari nano- $\mathrm{CaCO}_{3}$ yang ditambahkan.

Penggunaan nanofiller precipitated calcium carbonate (NPCC) pada campuran ABS/PC belum pernah diteliti. Tujuan penelitian ini adalah untuk mempelajari pengaruh perbandingan plastik ABS dan PC serta jumlah bahan pengisi NPCC terhadap sifat fisis nanokomposit ABS/ PC.

\section{BAHAN DAN METODE \\ Bahan Penelitian}

Bahan penelitian terdiri atas resin ABS merek Chi Mei dari China, resin PC merek Chi Mei dari China, NPCC merek Shengke dengan spesifikasi NPCCA-602 bentuk partikel kubus, ukuran partikel rata-rata $60 \mathrm{~nm}$, dan permukaannya sudah dicoating dengan coupling agent. Bahan aditif lain yang digunakan adalah aditif komersial maleat anhidrat (MA) sebagai compatibilizer, dicumyl phthalate (DCP) sebagai inisiator, serat gelas (fiber glass) sebagai penguat (reinforcing filler), anti oksidan, heat stabilizer, impact modifier merek Flexibilizer 4030, dan asam stearat.

\section{Peralatan Penelitian}

Alat proses yang digunakan dalam penelitian ini meliputi Laboplastomill internal mixer merek Toyoseiki dan hydraulic press merek 
Gonno. Alat uji meliputi: tensile strength tester merek Troning Albert tipe QC II-M-18, hardness tester merek Toyoseiki (Durometer D), dan Scanning Electron Microscopy (SEM) merek JEOL.

\section{Metode Penelitian \\ Pembuatan nanokomposit}

Nanokomposit dibuat dengan bahan baku ABS dan PC. Pada penelitian ini digunakan perbandingan $\mathrm{ABS} / \mathrm{PC} 100 / 0 ; 90 / 10 ; 80 / 20$; dan $70 / 30$. Selain itu juga digunakan nanofiller NPCC yang jumlahnya divariasi sebanyak 2,5 dan 5 $\mathrm{phr}(\mathrm{phr}=$ per hundred resin). Sebagai kontrol juga dibuat komposit $\mathrm{ABS} / \mathrm{PC}$ tanpa nanofiller NPCC. Bahan aditif lainnya ditambahkan dalam jumlah tetap. Compatibilizer yang digunakan adalah MA sebanyak $5 \mathrm{phr}$, DCP sebanyak 15\% MA, impact modifier untuk ABS sebanyak 5\% dari ABS, bahan pengisi serat gelas (fiber glass) sebanyak $20 \mathrm{phr}$, antioksidan $1 \mathrm{phr}$, asam stearat sebagai pelumas $3 \mathrm{phr}$, dan heat stabilizer $1 \mathrm{phr}$. Plastik ABS, PC, nanofiller dan aditif lainnya seperti formula yang ditetapkan dicampur dalam Laboplastomil internal mixer pada suhu $200^{\circ} \mathrm{C}$ dalam waktu total 10 menit, dengan torsi $60 \mathrm{rpm}$. Komposit yang diperoleh selanjutnya dibuat bentuk lembaran (slab) untuk sampel uji menggunakan alat hydraulic press pada suhu $200^{\circ} \mathrm{C}$ dalam waktu 10 menit.

\section{Pengujian}

Pengujian sifat fisikananokompositmeliputi uji ketahanan pukul takik dengan metode ASTM D 256 (metode Izod), uji densitas dengan metode ASTM D792, uji kekuatan tarik dan kemuluran sesuai ASTM D 638, 1991. Sifat kekerasan diuji mengacu ASTM D2240. Homogenitas dispersi nanofiller NPCC di dalam komposit diamati melalui Scanning Electron Microscope (SEM). Pengamatan morfologi nanokomposit melalui SEM dilakukan menggunakan metode secondary electron image dengan perbesaran 3500x.

\section{HASIL DAN PEMBAHASAN}

\section{Sifat Fisis Nanokomposit ABS/PC dengan Filler NPCC}

Hasil uji ketahanan pukul, uji kuat tarik, perpanjangan putus, densitas dan kekerasan, disajikan pada Gambar 1 sampai dengan Gambar 5. Gambar 1 memperlihatkan bahwa peng- gunaan PC sampai dengan $10 \mathrm{phr}$ tanpa nanofiller NPCC secara umum menaikkan ketahanan pukul komposit. Hal ini dikarenakan PC mempunyai nilai ketahanan pukul lebih tinggi dari ABS. Pada komposit yang hanya berisi ABS tanpa PC terlihat bahwa nanofiller NPCC memberi pengaruh yang positif artinya dengan penambahan NPCC menaikkan sifat ketahanan pukul. Hal ini juga sesuai dengan hasil penelitian Wang et al. (2008) menyatakan bahwa nanopartikel $\mathrm{CaCO}_{3}$ pada kisaran jumlah tertentu dapat menjaga atau menaikkan ketahanan pukul dari nanokomposit $\mathrm{CaCO}_{3} / \mathrm{EVA} / \mathrm{ABS}$. Penambahan NPCC untuk nanokomposit dengan ABS/PC lebih dari 90/10 menurunkan ketahanan pukul, ini diduga terjadinya penurunan interaksi dari NPCC dengan plastik ABS/PC akibat banyaknya bahan pengisi yang mengisi rongga kosong diantara polimer. Hal ini sejalan dengan pendapat Eiras and Pessan (2009) yang menyatakan bahwa adanya nanofiller $\mathrm{CaCO}_{3}$ menaikkan ketahanan pukul nanokomposit polipropilen, namun semakin tinggi jumlah nanofiller $\mathrm{CaCO}_{3}$ yang ditambahkan akan menurunkan ketahanan pukul.

Pada pencampuran ABS/PC, NPCC hanya mempunyai efek positif pada rasio $\mathrm{ABS} / \mathrm{PC}$ 90/10 dengan jumlah NPCC 2,5 phr. Ketahanan pukul tertinggi $\left(7.360 \mathrm{~J} / \mathrm{cm}^{2}\right)$ diperlihatkan oleh komposit yang berisi ABS $100 \mathrm{phr}$ dan nanofiller $5 \mathrm{phr}$, sedangkan urutan kedua dengan nilai ketahanan pukul $5.030 \mathrm{~J} / \mathrm{cm}^{2}$ diberikan oleh komposit yang berisi ABS $90 \mathrm{phr}$, PC $10 \mathrm{phr}$ dan nanofiller 2,5 phr.

Gambar 2 memperlihatkan bahwa penam-

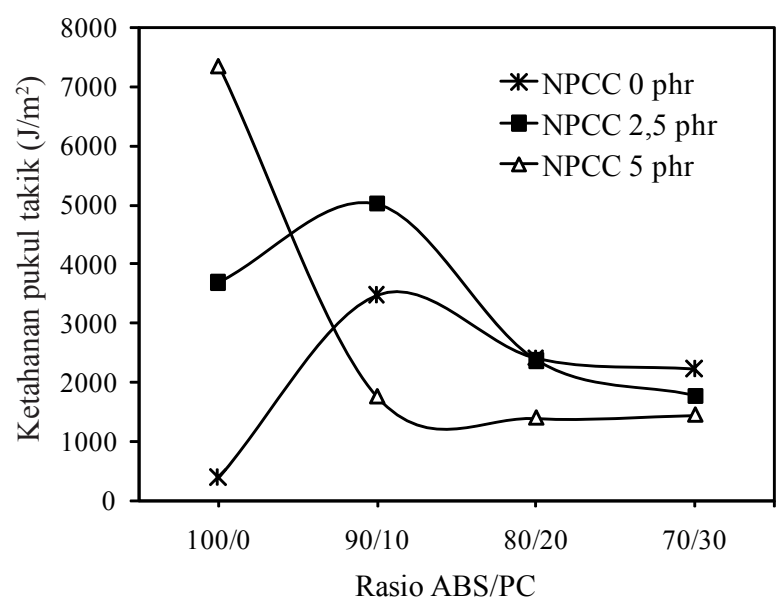

Gambar 1. Ketahanan pukul takik nanokomposit 


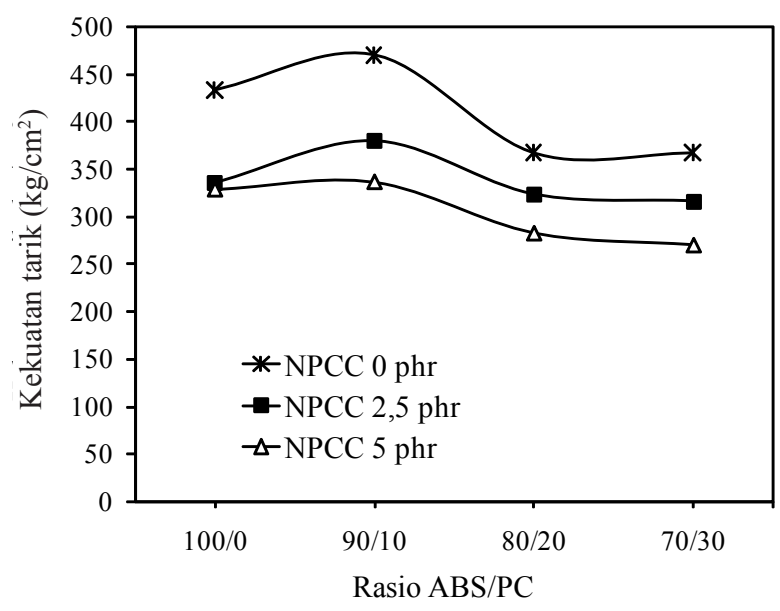

Gambar 2. Kuat tarik komposit

bahan nanofiller NPCC menurunkan kuat tarik, penambahan polikarbonat sampai $10 \mathrm{phr}$ pada jumlah NPCC yang sama memberikan kuat tarik lebih tinggi. Sifat kuat tarik tertinggi yaitu sebesar $471,09 \mathrm{~kg} / \mathrm{cm}^{2}$ diberikan oleh komposit yang mempunyai perbandingan $\mathrm{ABS} / \mathrm{PC}=90 / 10$ tanpa nanofiller NPCC, sedangkan di urutan kedua untuk komposit yang mempunyai perbandingan $\mathrm{ABS} / \mathrm{PC}=90 / 10$, NPCC 2,5 phr dengan nilai kuat tarik $380,14 \mathrm{~kg} / \mathrm{cm}^{2}$. Dari Gambar 2 juga terlihat bahwa nanofiller NPCC tidak memberikan dampak positif pada sifat kuat tarik karena cenderung menurunkan sifat kuat tarik. Hal ini sama seperti yang dikemukakan oleh Wang et al. (2008) bahwa kuat tarik dari nanokomposit $\mathrm{CaCO}_{3} / \mathrm{EVA} / \mathrm{ABS}$ menurun dengan bertambahnya nanopartikel $\mathrm{CaCO}_{3}$. Penurunan kekuatan tarik diduga karena melemahnya ikatan nanopartikel dengan matriksnya (Kemal et al., 2009).

Nanofiller NPCC juga tidak memberikan efek positif terhadap sifat perpanjangan putus. Ini karena partikel filler semakin banyak yang mengisi rongga kosong antar molekul plastik sehingga menyebabkan mobilitas struktur plastik ABS/PC berkurang yang menyebabkan kemuluran juga berkurang. Keadaan tersebut menyebabkan penurunan gaya intermolekul antar rantai. Perpanjangan putus tertinggi sebesar 4,01\% juga diberikan oleh komposit yang mempunyai perbandingan $\mathrm{ABS} / \mathrm{PC}=90 / 10$ tanpa nanofiller NPCC (Gambar 3). Penambahan PC lebih dari $10 \mathrm{phr}$ juga cenderung menurunkan perpanjangan putus komposit.

Densitas suatu material berkaitan dengan

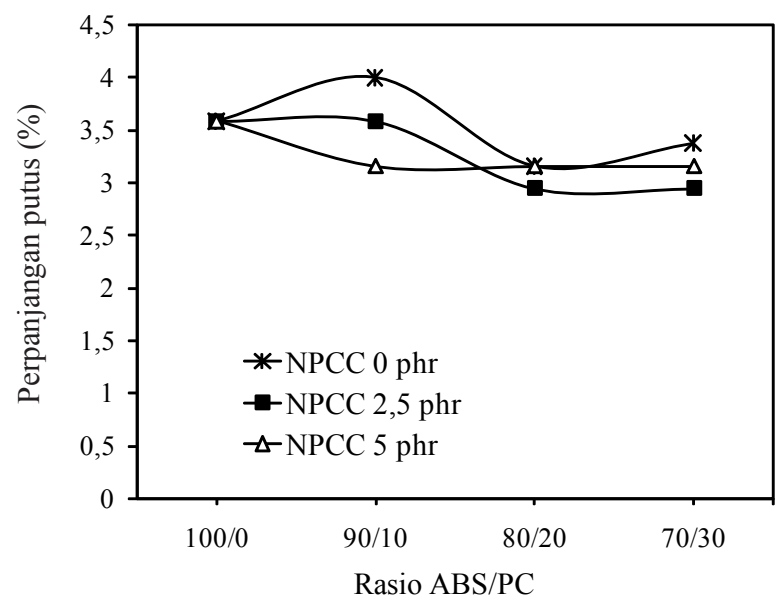

Gambar 3. Perpanjangan putus komposit

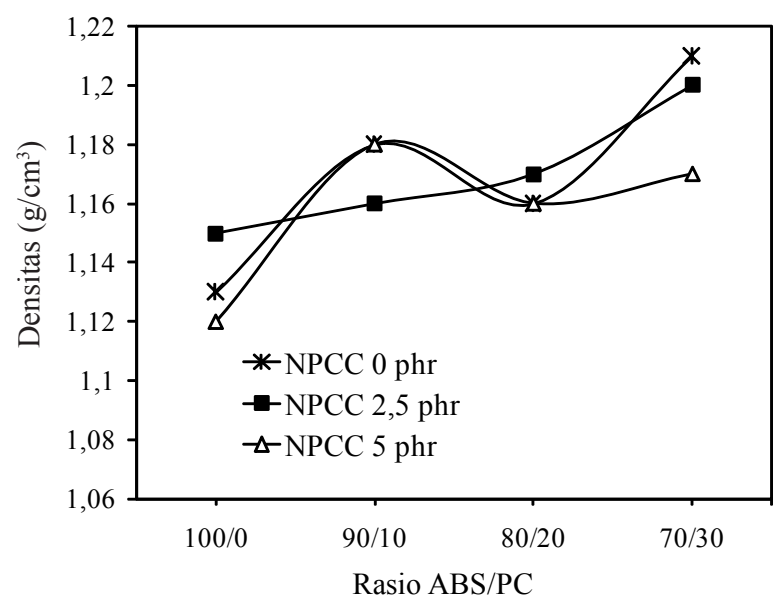

Gambar 4. Densitas nanokomposit

kerapatan partikelnya, dalam penelitian ini adalah kerapatan antara partikel nanofiller NPCC, plastik ABS/PC sebagai matriks nanokomposit, juga bahan aditif lain sebagai bahan penyusunnya. Gambar 4 memperlihatkan pengaruh NPCC terhadap densitas nanokomposit ABS/PC.

Penambahan PC secara umum menaikkan densitas nanokomposit karena sifat PC yang mempunyai densitas lebih tinggi dari ABS. Densitas nanokomposit hasil penelitian mempunyai kisaran antara $1,12-1,21 \mathrm{~g} / \mathrm{cm}^{3}$.

Densitas tertinggi diberikan oleh komposit tanpa NPCC (kontrol) yang mempunyai kandungan $\mathrm{ABS} / \mathrm{PC} 70 / 30$. Densitas terendah diberikan oleh nanokomposit yang tidak berisi PC dengan kandungan NPCC $5 \mathrm{phr}$.

Dibandingkan dengan kontrol maka penambahan NPCC 2,5 phr menaikkan densitas sebesar $1,77 \%$ untuk nanokomposit yang hanya berisi ABS, $0,86 \%$ untuk nanokomposit dengan 
kandungan $\mathrm{ABS} / \mathrm{PC} 80 / 20$, dan menurunkan densitas sebesar $1,7 \%$ untuk rasio $\mathrm{ABS} / \mathrm{PC}$ 90/10, dan 0,83\% untuk nanokomposit dengan ABS/PC 70/30. Penambahan NPCC 5 phr menurunkan densitas sebesar $0,88 \%$ untuk nanokomposit yang hanya berisi $\mathrm{ABS}, 3,306 \%$ untuk komposit dengan kandungan $\mathrm{ABS} / \mathrm{PC} 70 / 30$, dan tidak terjadi perubahan densitas untuk komposit dengan kandungan ABS/PC 90/10 dan ABS/PC 80/20. Densitas NPCC adalah $0,48 \mathrm{~g} / \mathrm{cm}^{3}$, ini berarti semakin banyak NPCC yang ditambahkan seharusnya densitas semakin menurun pada ukuran sampel uji yang sama. Data densitas nanokomposit hasil penelitian yang disajikan pada Gambar 4 bervariasi seperti dijelaskan di atas. Namun berdasarkan analisis statistik, penambahan nanofiller NPCC 0; 2,5; dan $5 \mathrm{phr}$ tidak berpengaruh nyata terhadap

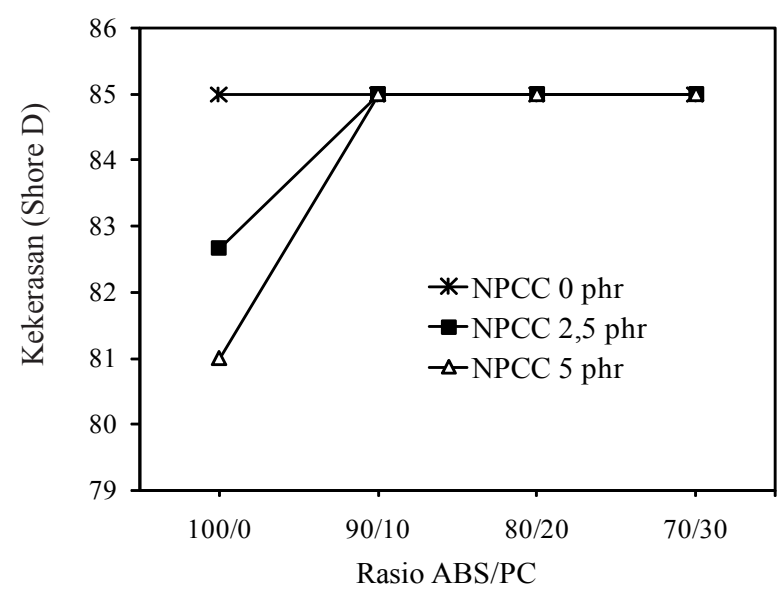

Gambar 5. Kekerasan nanokomposit densitas nanokomposit hasil penelitian $(\mathrm{p}<0,5)$.

Gambar 5 memperlihatkan bahwa nanokomposit yang hanya berisi $\mathrm{ABS}$, penambahan nanofiller NPCC menurunkan kekerasan, namun pada komposit yang berisi $\mathrm{ABS} / \mathrm{PC}$ jumlah nanofiller NPCC yang ditambahkan sebanyak 2,5 dan 5 phr tidak mempengaruhi kekerasan nanokomposit pada berbagai perbandingan ABS/PC, dimana nilai kekerasan nanokomposit adalah 85 Shore D.

\section{Morfologi Nanokomposit ABS/PC dengan Filler NPCC}

Analisis SEM terhadap struktur mikro bahan komposit digunakan untuk memantau distribusi bahan pengisi, NPCC, dan aditif lain dalam matriks polipaduan ABS dan PC. Mikrograf SEM dari resin ABS, PC, dan komposit hasil penelitian disajikan pada Gambar 6. Morfologi campuran $\mathrm{ABS} / \mathrm{PC}$ adalah kompleks dan tergantung pada komposisi, tipe ABS dan $\mathrm{PC}$ dan interaksi interfacial-nya. Gambar 5(c), 5(d), 5(e), dan 5(f) memperlihatkan bahwa bahan penyusun komposit tercampur homogen dan tidak terlihat NPCC teraglomerasi. Penambahan PC sampai 20 phr (Gambar 5(f)) juga memperlihatkan pencampuran yang homogen dimana PC terdispersi sebagai bercak didalam matriks ABS.

\section{KESIMPULAN DAN SARAN}

Komposit plastik hasil penelitian terbaik ditinjau dari sifat ketahanan pukul dan kuat tarik
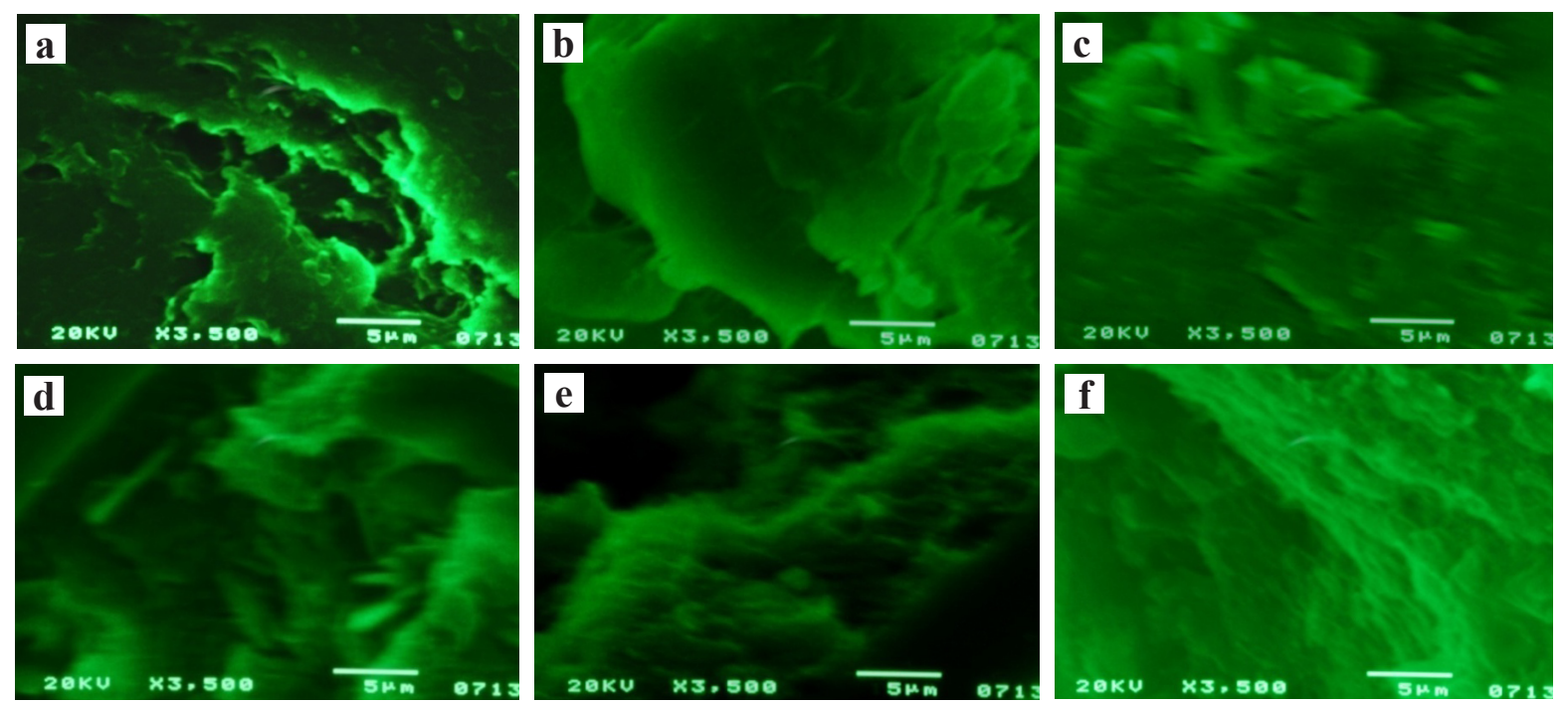

Gambar 6. Mikrograf SEM dari: (a) ABS, (b) PC, (c) Komposit yang berisi ABS/PC/NPCC: 100/0/0, (d) Komposit yang berisi ABS/PC/NPCC: 100/0/5, (e) ABS/PC/NPCC: 90/10/5, (f) ABS/PC/NPCC: 80/20/5 
adalah komposit yang berisi $\mathrm{ABS} / \mathrm{PC}=90 / 10$ dengan nanofiller NPCC 2,5 phr dengan hasil uji kuat tarik $380,14 \mathrm{~kg} / \mathrm{cm}^{2}$, perpanjangan putus $3,59 \%$, ketahanan pukul $5030 \mathrm{~J} / \mathrm{m}^{2}$, densitas 1,16 $\mathrm{g} / \mathrm{cm}^{3}$, dan kekerasan 85 Shore D. Penambahan nanofiller NPCC tidak memberikan efek positif pada sifat kuat tarik, perpanjangan putus, densitas, dan kekerasan dari campuran ABS/PC, tetapi menaikkan sifat ketahan pukul campuran ABS/PC untuk penambahan sampai 2,5 phr. Uji morfologi dengan SEM memperlihatkan bahan penyusun komposit tercampur homogen dan tidak terlihat NPCC teraglomerasi.

\section{UCAPAN TERIMA KASIH}

Penulis mengucapkan terimakasih kepada Kepala Balai Besar Kulit, Karet dan Plastik yang telah memberi kepercayaan untuk melakukan penelitian serta kepada Tim Pokja 1866.001.004.043 yang membantu selama penelitian.

\section{DAFTAR PUSTAKA}

Abubakar, A. and Rosli, N. N. M., 2006. Effect of nano-precipitated calcium carbonate on mechanical properties of PVC-U and PVC-U/acrylic blend, Jurnal Teknologi, 45(F): 83-93.

Chao, L. Y., Zheng, Y. L., Wei, Y., Jian, M. F., and Ming, B Y., 2009. Effect of processing method on morphological and rheological properties of $\mathrm{PC} / \mathrm{CaCO}_{3}$ nanocomposites, Polymer-Plastics Technology and Engineering, 48(8): 788-793.

Eiras, D. and Pessan, L.A., 2009, Mechanical properties of polypropylene/calcium carbonate nanocomposites, Materials Research, 12(4): 517-522.

Farzadfar, A. and Khorasani, S. N., 2011. Investigation on mechanical properties of $\mathrm{PC} / \mathrm{ABS}$ blends in presence of ABSg-MAH as a compatibilizer, Polymer Processing Society 2011 Asia/Australia Regional Meeting, Kish Island.
Gupta, R. K., and Bhattacharya, S. N., 2008. Polymer-clay nanocomposites: current status and challenges, Indian Chemical Engineer, 50(3): 242-267.

Hassan, A. and Jwu, W. Y., 2005. Mechanical properties of high impact $\mathrm{ABS} / \mathrm{PC}$ blends effect of blend ratio, Polymer Symposium, Kebangsaan Ke-V, Malaysia.

Kemal,I. Whittle, A.,Burford,R., Vodenitcharova, T., and Hoffman, M., 2009. Toughening of unmodified polyvinylchloride through the addition of nanoparticulate calcium carbonate, Polymer, 50: 4066-4079.

Krache, R. and Debbah, I., 2011. Some mechanical and thermal properties of PC/ABS blends, Materials Sciences and Applications, 2: 404-410.

Mahanta, D., Dayanidhi, S. A., Mohanty, S., and Nayak, S. K., 2012. Mechanical, thermal, and morphological properties of recycled polycarbonate/recycled poly(acrylonitrilebutadiene-styrene) blend nanocomposites, Polymer Composites, 33(12): 2114-2124.

Pueakbuakhao, N., Prissanaroon-Quajai, W., and Kreua-Ongarjnukool, N., 2008. Effect of coupling agents on mechanical properties and morphology of $\mathrm{CaCO}_{3}$-filled recycled high density polyethylene, Journal of Metal, Materials and Minerals, 18(2): 131135

Wang, W. Y., Wang, G. Q., Zeng, X. F., Shao, L., and Chen, J. F., 2008. Preparation and properties of nano- $\mathrm{CaCO}_{3}$ /acrylonitrilebutadiene-styrene composites, Journal of Applied Polymer Science, 107: 3609-3614. 